\title{
Efficacy and predictive factors of response to intra-articular corticosteroids in knee osteoarthritis
}

\author{
Parnaz Heidari ${ }^{1}$, Behzad Heidari ${ }^{2}$, Mansour Babaei ${ }^{3,4}$ \\ ${ }^{1}$ Sina Clinic Hospital, Babol, Iran \\ ${ }^{2}$ Mobility Impairment Research Center, Babol University of Medical Sciences, Iran \\ ${ }^{3}$ Clinical Research Development Unit, Rouhani Hospital, Babol University of Medical Sciences, Iran \\ ${ }^{4}$ Department of Rheumatology, Rouhani Hospital, Babol University of Medical Sciences, Iran
}

\begin{abstract}
In knee osteoarthritis (KOA), synovial inflammation is linked with pain, swelling and structural abnormalities. Intra-articular corticosteroids (IACS) have been considered for pain relief in subjects who are non-responders to standard therapy. However, the results vary across different studies. This review aims to determine efficacy of IACS in KOA by review of the existing data.

In several randomized controlled trials (RCTs), meta-analyses and uncontrolled studies a single IACS resulted in pain relief from 1 to a few weeks. In a few studies repeated IACS every three months provided a longer duration of pain relief and functional improvement in a proportion of patients. Baseline synovitis was predictor of treatment response in some but not all studies.

Based upon the existing data, IACS provides a short-term pain relief in a proportion of patients. Given, anti-inflammatory properties of IACS, it is likely to be more effective in subgroups of KOA who display inflammatory phenotype.
\end{abstract}

Key words: knee osteoarthritis, intra-articular corticosteroid, synovitis, pain, efficacy, predictor.

\section{Introduction}

Knee osteoarthritis (KOA) is a chronic slowly progressive and debilitating condition, which is characterized by pain, limitation of physical activity. It is a leading cause of disability, impaired quality of life and activities of daily living [1].

Traditionally, knee osteoarthritis is considered as a degenerative disease because of cartilage degeneration, loss of joint space and osteophyte formation in radiography, but recent observations indicate existence of an inflammatory process which involves the whole tissues of the joint, and contributes to the development of symptoms and progression of structural changes [2, 3].

Mechanical and biochemical factors are also responsible for the development of synovitis, cartilage breakdown, osteophytes formation, subchondral bone sclerosis and alterations in the joint capsule [3]. Synovial membrane inflammation is important, because it is linked with symptoms such as joint pain, effusion, joint dysfunction, and progression of structural changes and cytokines abnormalities [4-7].

Reduction of osteoarthritic pain by anti-inflammatory drugs supports an association between inflammatory process and pain. However, response to anti-inflammatory drugs in KOA is complex. It is partly dependent on the patterns of clinical symptoms, type of involved joints and responsible factors of pain [8, 9]. Existing data suggest that targeting synovial inflammation at early stage of KOA may provide a possible beneficial effect in delaying cartilage damage or osteophytes formation $[4,5,10]$.

Several treatment guidelines have been established to relieve pain, improve function and prevent clinical exacerbation in knee osteoarthritis [11]. Multiple medications including systemic and local non-steroidal antiinflammatory drugs (NSAIDs), acetaminophen, opioids which have been considered for treatment of KOA are effective only in a proportion of patients. 
In non-responders to standard therapy, particularly in patients with joint effusion, many drugs are administrated through intra-articular injection to attain a rapid benefit through direct effect on synovial inflammation [11, 12].

About $50 \%$ of patients with KOA have synovitis and joint effusion at the time of arthroscopy. Severity of synovitis correlates positively with pain, and shrinkage of synovial tissue volume correlates with treatment response $[13,14]$. Hence, suppression of synovial inflammation has been considered as the main target of treatment for pain relief [10].

Unlike most osteoarthritis drugs, intra-articular corticosteroids (IACS) are safe, inexpensive and well tolerated by patients. Because of their moderate analgesic effect, they can be considered for pain relief in patients who are not responsive to conventional medications [15].

The beneficial effect of intra-articular corticosteroid in KOA is assumed to be mediated through its antiinflammatory effect against synovial inflammation which is an integral part of osteoarthritis (OA) process. However, efficacy of intra-articular corticosteroids in KOA depends upon the presence, extent and severity of synovitis and its association with pain $[14,16]$. However, the prevalence of synovitis varies across different study populations and is dependent to its definition and diagnostic methods [17, 18].

At present, it is not possible to determine which patients gain the most therapeutic benefits from IACS treatment. Based on anti-inflammatory characteristics of IACS, it is hypothesized that, patients with knee joint synovitis and effusion, or KOA patients with clinical exacerbations will attain greater benefit from IACS therapy.

In particular, individuals with minimal cartilage destruction are expected to attain most improvement in knee function [10, 11]. However, the results of many meta-analyses and RCTs which addressed efficacy of IACS in KOA are conflicting, and the outcomes of treatment vary from no efficacy or little short duration of improvement in pain and/or joint function to a few or several weeks of pain relief [14, 16, 19-21].

Inconsistent results can be attributed to variations in study design, outcome measures, patients selection, treatment strategy, duration of follow-up period. Other factors such as presence or absence of synovitis, joint effusion, severity of structural lesions, severity of synovial inflammation, sources of pain, accuracy of intra-articular injection can also affect treatment responses [8, 22].

Even intra-articular injection of normal saline, or joint fluid aspiration itself can provide pain relief $[7,16]$. A meta-analysis of 32 studies involving 1705 patients revealed a significant long-term pain reduction by intra- articular injection of normal saline in patients with knee osteoarthritis [23].

Yet, it is difficult to predict the therapeutic effect of IACS, and to discriminate patients who are responders or non-responders. Hence this narrative review aims to elucidate the effect of IACS in KOA and to recognize the factors that predict treatment response by review of the existing data. Treatment response was defined as pain relief or significant pain reduction with or without functional improvement for one week or longer duration after IACS therapy or prevention of structural progression in long-term studies.

For these purposes, English language databases were searched as recommended to identify potential studies which have been published in Medline/PubMed, Scopus and Google Scholar since 2000 by using keywords such as knee osteoarthritis, synovitis, effusion, intra-articular corticosteroid, efficacy, treatment, pain relief, functional improvement, predictors. In addition the references of the selected papers were searched to find eligible studies.

Studies in which pain relief with or without functional improvement or changes in pain was considered as an outcome and was evaluated by either Visual Analogue Scale (VAS) or Western Ontario and McMaster Universities OA Index (WOMAC), or other valid measures were selected. Studies without pain assessment were excluded.

A total of 345 studies were found which 219 papers were irrelevant based on the titles and so were excluded. Among 126 remaining full-text 93 studies were not eligible due to lack of interested data and removed. A total of 33 full-texts which have been found to be interest were selected for analysis (Fig. 1).

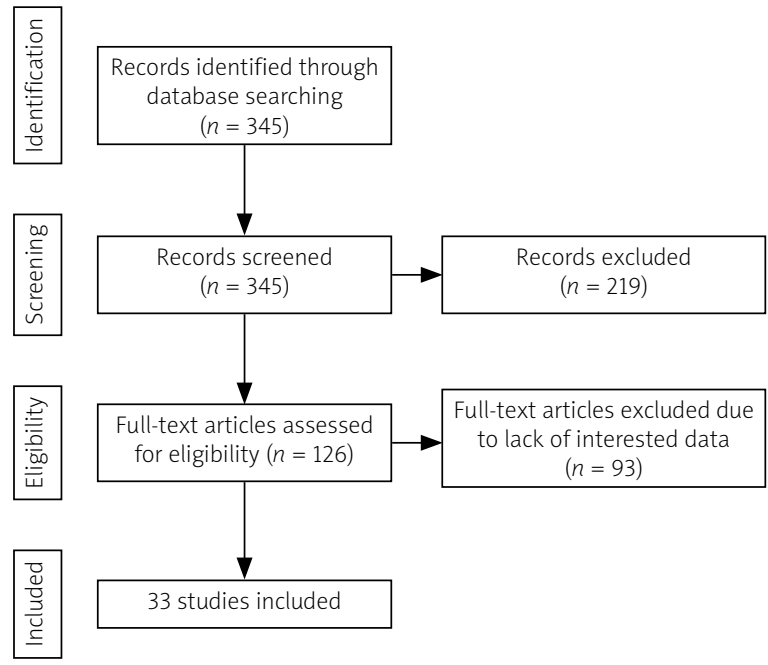

Fig. 1. Flow diagram of selected studies. 
All relevant sources were critically analyzed to ensure diversity in the sources and to avoid bias [24]. The selected studies were categorized according to study designs and the results were presented under subheadings in relation to the diagnosis and prevalence of synovitis, synovitis and pain, efficacy of IACS and predictors of treatment response.

\section{Diagnosis of synovitis}

The diagnosis of knee synovitis is important for identification of patients who are likely to benefit from IACS therapy. Fluctuations in synovial inflammation and joint effusion can be a sign of KOA flare or treatment response. Arthrocentesis is the best method for the diagnosis and quantification of joint effusion, but this measure is invasive and painful. Accurate estimation of total effusion by joint aspiration is often impossible [25].

A clinical diagnosis of synovitis is suspected in the presence of a swollen joint with effusion, redness, warmness, and pain. However, clinical detection of synovitis at early stage of KOA is difficult because of low specificity as well as low intraobserver and interobserver reliability of clinical examination [26].

Existence and extent of synovial inflammation can be also confirmed by ultrasonography and MRI, even in subjects with few symptoms or without clinical synovitis who have limited cartilage or subchondral bone lesions.

Moreover, synovitis can be detected as changes in thickening of synovium or localized proliferative changes by arthroscopic examination of the knee joint [4].

\section{Prevalence of synovitis in knee osteoarthritis}

Synovial abnormalities have been shown in different stages of osteoarthritis and existing data indicate an important role for synovial abnormalities in the pathogenesis of osteoarthritis [27].

About $50 \%$ of patients with KOA have synovial inflammatory changes such as thickening of synovium or localized proliferative changes [4]. Application of sensitive imaging technics and tissue examination indicated a high prevalence of synovial inflammation in all stage of osteoarthritis [1].

Nonetheless, the prevalence of synovitis in $\mathrm{KOA}$ varies across different studies according to diagnostic measures. In one large study of patients with symptomatic KOA, $46 \%$ of patients had synovial inflammation or joint effusion on sonographic examination [17]. By using contrast-enhanced as well as non-enhance magnetic resonance imaging (MRI), synovitis was detected in $70 \%$ of patients without joint effusion and in more than $95 \%$ of patients with knee joint effusion [18]
A meta-analysis of 24 observational studies revealed a pooled prevalence of ultrasound detected synovial effusion, synovial hypertrophy, and Doppler signal in $51.5 \%, 41.5 \%$, and $23.5 \%$ of people with $\mathrm{KOA}$ and pain respectively [28].

\section{Association between synovitis and pain in knee osteoarthritis}

In patients with KOA several parameters including synovitis, joint effusion, meniscal tears and bone marrow lesions are associated with pain [29].

Wang et al. [27] found an independent association between MRI-detected synovitis and pain in a large cross-sectional and longitudinal study of patients with knee osteoarthritis [30].

Another longitudinal study found a relationship between fluctuations of synovitis and change in pain and cartilage volume in knee osteoarthritis. In this study changes in pain and synovial inflammation were assessed by VAS and MRI at baseline, 15 months and 30 months later. The strongest correlation was observed between pain and infrapatellar synovitis [31].

In one study, $80 \%$ of patients with moderate pain had synovitis, and there was a strong correlation between severity of pain and synovitis detected with dynamic contrast-enhanced MRI (DCE-MR). In patients with synovitis pain was 9.2 times greater than those without synovitis [32]. However, knee pain can occur in the absence of synovitis or effusion due to bone marrow lesions or intra-articular pathology [33].

\section{Efficacy of intra-articular corticosteroids in knee osteoarthritis}

\section{Effect on knee pain and function}

Most studies including RCTs, systematic review and uncontrolled clinical trials which have addressed the effect of IACS in symptomatic KOA (Table I and II) found a beneficial effect of treatment on pain, joint function, walking time as well as in range of joint motion $[14,16,34-46]$. However, these studies differ in regard to treatment outcomes and outcome measures, duration of studies and the number of IACS injections.

Raynauld et al. [36] in a 2-year RCT of 68 patients with symptomatic KOA compared the effect of intraarticular triamcinolone hexacetonide (IATH) on pain score, night pain, range of motion and changes in joint space.

In this study repeated injections of IATH every 3 months over 2 years of the study period were safe and clinically effective on night pain and range of motion until 1 year after initiation of treatment as determined by total score on the WOMAC, physician's global assess- 


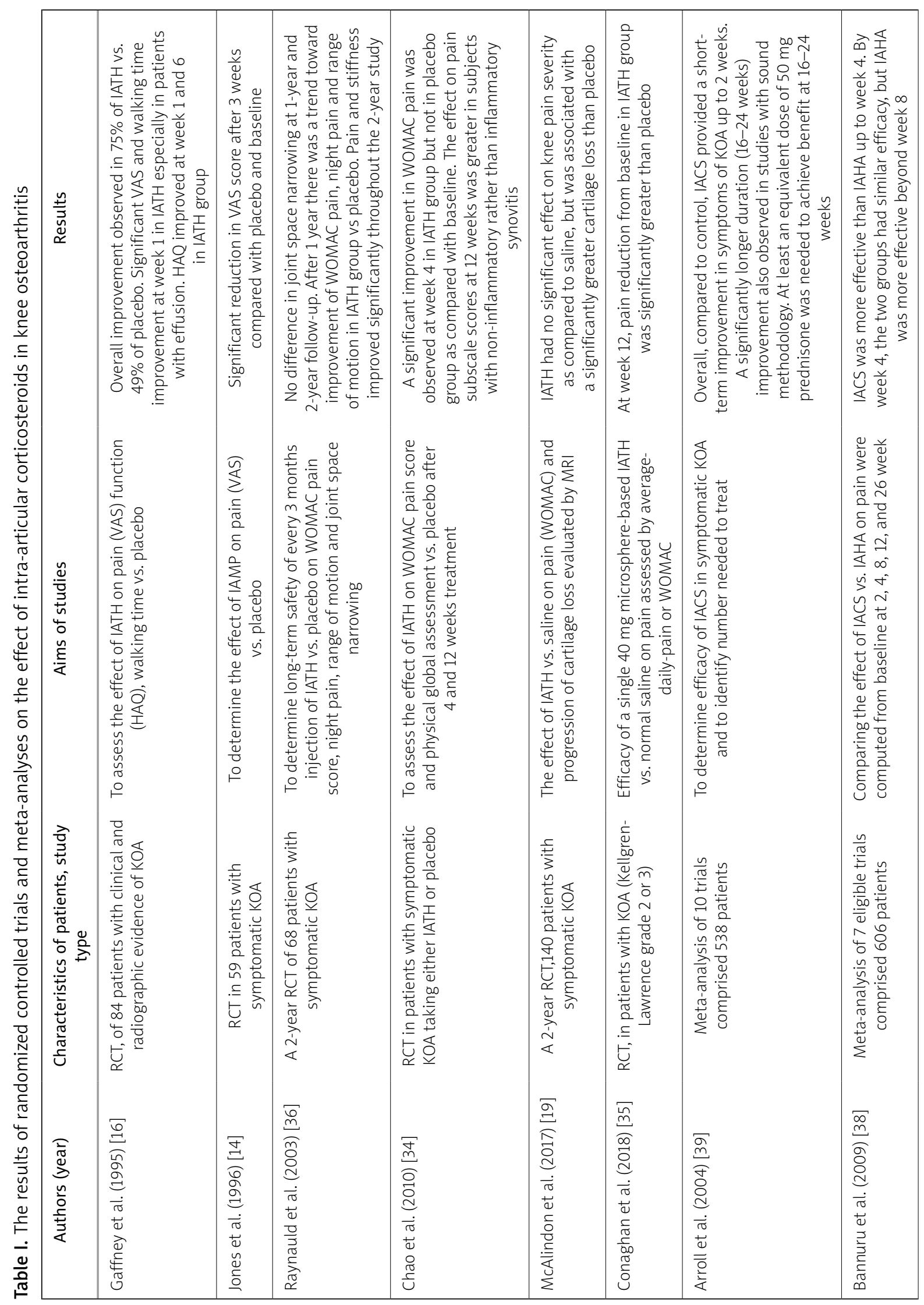




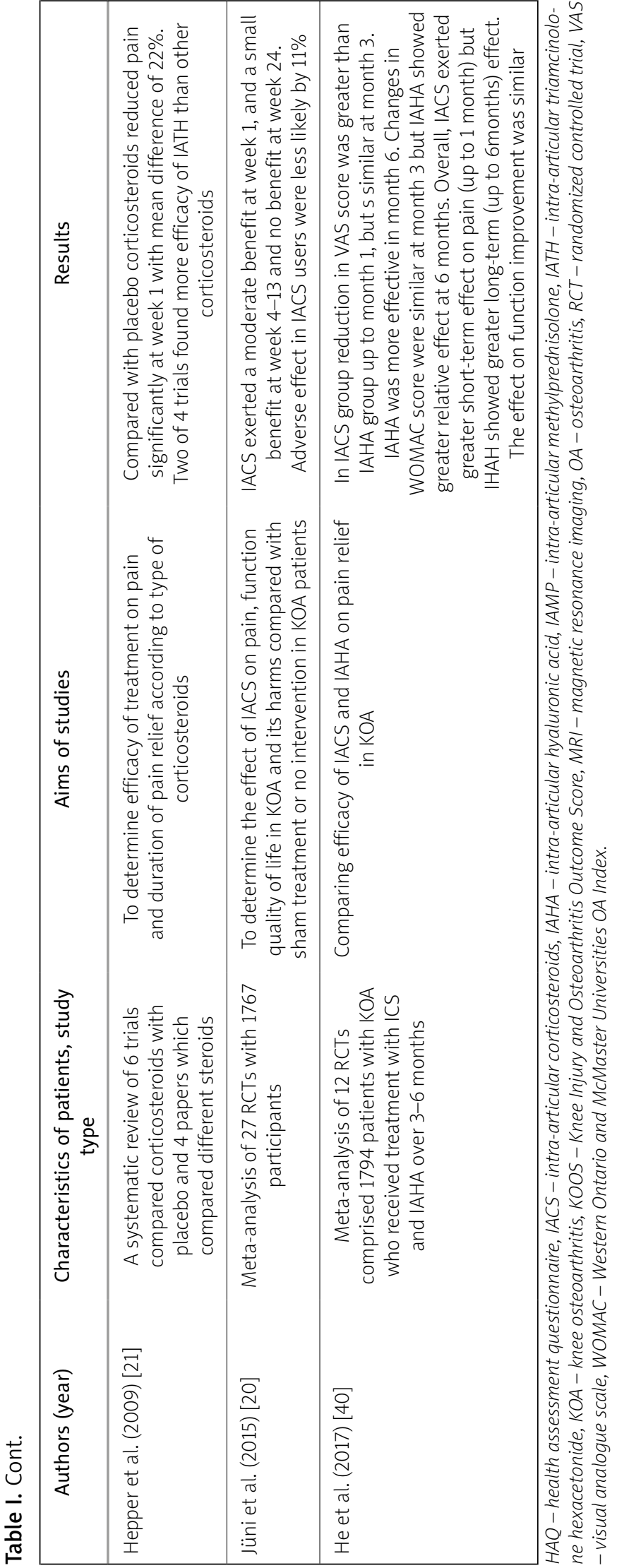

ment, patient's global assessment, patient's assessment of pain, range of motion of the affected knee, and 50-foot walking time as assessed before each injection [36].

However, McAlindon et al. [19] in another RCT of patients with symptomatic KOA found no significant effect of every 3 months injections of IATH on severity of pain as compared with saline by using WOMAC osteoarthritis index collected every 3 months.

Nevertheless, 4 randomized controlled trials which assessed the effect of a single IATH or intra-articular methylprednisolone (IAMP) on knee pain and clinical symptoms of KOA, found greater improvement of pain, function, stiffness and walking time in the treatment group as compared with placebo [14, 16, 25, 34].

In one of these randomized controlled trial, a single injection of IATH resulted in improvement of pain, function health assessment questionnaire ( $\mathrm{HAQ}$ ) and walking time in $75 \%$ of patients in IATH group vs. $45 \%$ of the placebo group. However, duration of efficacy was short and treatment response was mostly observed in patients with joint effusion [16].

Several uncontrolled clinical trials have also shown efficacy of a single IACS injection on pain, stiffness, physical activities and quality of life in knee osteoarthritis (Table II) [10, 12, 23, 37, 41, 43-47].

In an uncontrolled open-label clinical trial of 71 patients with symptomatic KOA, who presented with history of knee joint swelling, effusion and night pain for at least 3 months. Four weeks after treatment with a single injection of IACS, proportion of patients with joint effusion, night pain, limitation of physical activity, and functional capacity decreased from 100\%, 95\%, 75\%, and $80 \%$ at baseline to $5 \%, 2 \%, 25 \%$, and $45 \%$ at endpoint respectively [12].

A comparative study which compared the effect of IACS and intra-articular hyaluronic acid (IAHA) on pain relief between users and non-users, indicated that longterm administration of one or more intra-articular injection of IACS over a 2-year follow-up period had no effect on knee pain, stiffness and function as compared with non-users [37]. The beneficial effects of IACS on pain, function and quality of life have been also shown in several meta-analyses [20, 21, 38-40]. In all studies improvement of symptoms in IACS group was significantly higher than the placebo group (Table I).

The average duration of pain relief or pain reduction in RCTs and meta-analyses, as well as in uncontrolled clinical trials varied from 1 or 2 weeks to as long as 3-24 weeks [10, 12, 42-46].

Sample size, duration of treatment, sensitivity of outcome measures, and type of treatment outcome can differently affect the results and limit detection of real difference across studies, as well as between the treat- 


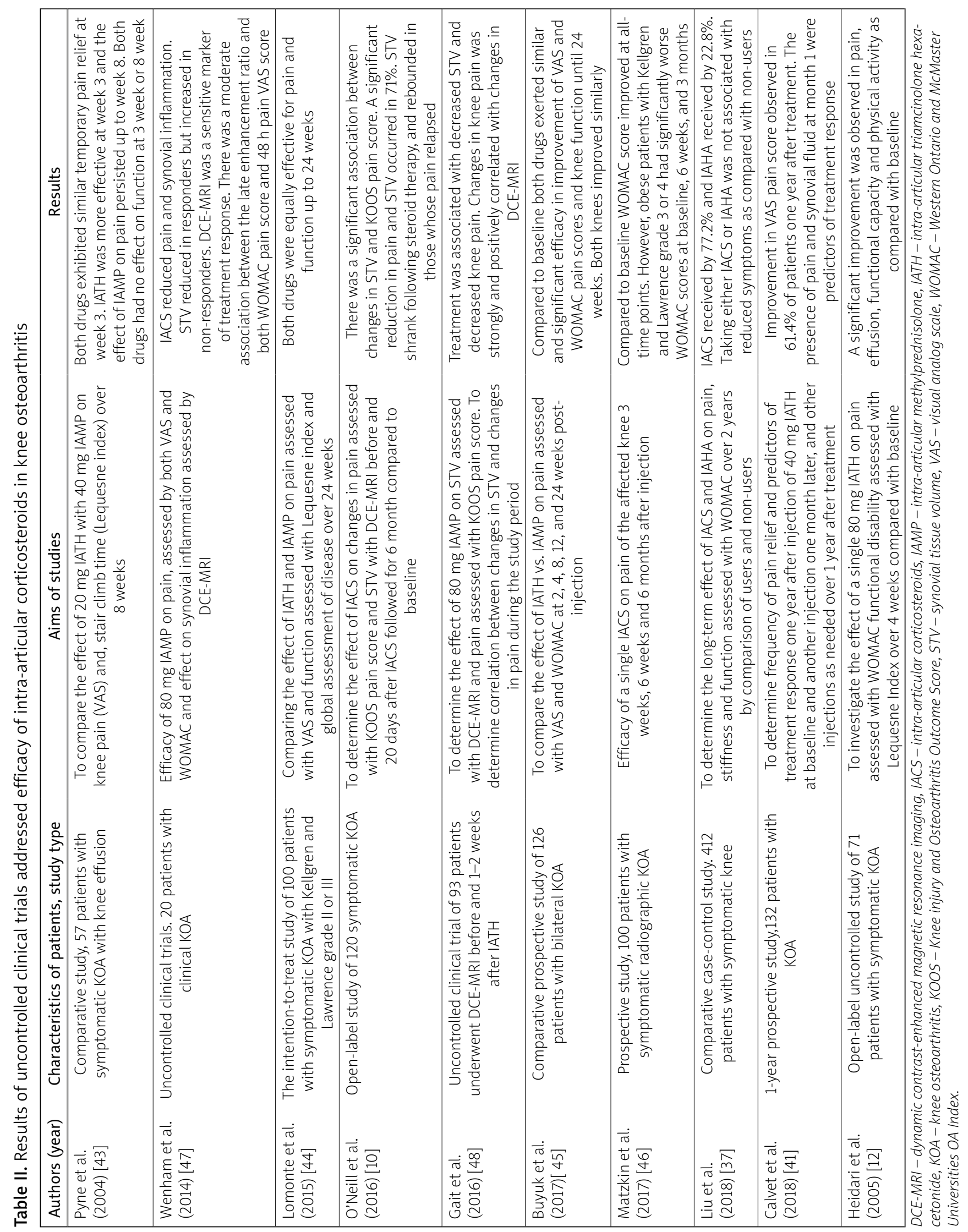


Table III. Randomized controlled trials and meta-analyses studies addressed predictors of response to intra-articular corticosteroids in knee osteoarthritis

\begin{tabular}{|c|c|c|c|}
\hline Authors (year) & Type and purpose of studies & Treatment outcomes & Predictors of response to treatment \\
\hline $\begin{array}{l}\text { Gaffney et al. } \\
\text { (1995) [16] }\end{array}$ & $\begin{array}{c}\text { Uncontrolled clinical trial in } 84 \\
\text { patients with KOA }\end{array}$ & Clinical improvement & $\begin{array}{l}\text { Presence of joint effusion, joint } \\
\text { aspiration predicted outcome }\end{array}$ \\
\hline $\begin{array}{l}\text { Jones et al. } \\
\text { (1996) [14] }\end{array}$ & $\begin{array}{l}\text { RCT of } 59 \text { patients with } \\
\text { symptomatic KOA }\end{array}$ & $\begin{array}{l}\text { A significant short-term } \\
\text { reduction in knee pain as } \\
\text { compared with placebo group }\end{array}$ & No clinical predictor was found \\
\hline $\begin{array}{l}\text { Chao et al. } \\
\text { (2010) [34] }\end{array}$ & $\begin{array}{l}\text { RCT of } 40 \mathrm{mg} \text { IATH vs. } \\
\text { placebo in } 79 \text { patients with } \\
\text { symptomatic KOA }\end{array}$ & $\begin{array}{l}\text { Short duration of pain relief } \\
\qquad(4-12 \text { weeks })\end{array}$ & $\begin{array}{l}\text { Non-inflammatory synovial } \\
\text { hypertrophy }\end{array}$ \\
\hline $\begin{array}{l}\text { Hirsch et al. } \\
\text { (2013) [55] }\end{array}$ & A meta-analysis of 21 studies & $\begin{array}{l}\text { Identification of a predictor } \\
\text { response }\end{array}$ & $\begin{array}{l}\text { No predictor was found based on } \\
\text { radiographic findings, clinical or } \\
\text { sonographic evidence of inflammation } \\
\text { or synovial hypertrophy }\end{array}$ \\
\hline $\begin{array}{l}\text { Maricar et al. } \\
\text { (2013) [49] }\end{array}$ & A meta-analysis of 11 studies & $\begin{array}{c}\text { To address clinical efficacy of } \\
\text { treatment }\end{array}$ & $\begin{array}{c}\text { Presence of effusion, baseline severity } \\
\text { of symptoms }\end{array}$ \\
\hline
\end{tabular}

KOA - knee osteoarthritis, IATH - intra-articular triamcinolone hexacetonide, $R C T$ - randomized controlled trial.

ment and placebo group [14]. Furthermore, inaccessibility to synovial fluid during injection, and inadequate joint aspiration prior to injection of IACS can lead to insufficient treatment response and underestimation of IACS effect [16].

\section{Effect on structural changes}

A few studies have addressed the effect of IACS on progression of KOA (Table I and II). The results of two 2-year RCTs which have assessed the effect of IACS on structural changes in KOA were inconsistent $[19,36]$.

In one study repeated injections of IATH every 3 months was safe without any effect on radiographic joint space narrowing progression after 2 years [36], while, McAlindon et al. [19] in another 2-year RCT found significantly greater MRI detected cartilage volume loss in IATH treated patients as compared with placebo.

Contradictory results may be explained by lower sensitivity of radiography than MRI in detecting small structural changes. However, none of these studies as sessed changes in synovial tissue volume (STV) or severity of synovitis, which is the main cause of structural changes and progression [4, 10, 16, 34, 47, 48].

O'Neill et al. [10] in a prospective study of 120 symptomatic KOA found significant reduction of STV after an injection of $80 \mathrm{mg}$ IAMP. Compared with baseline, STV reduction was shown by dynamic contrastenhanced magnetic resonance imaging (DCE-MRI) in $71 \%$ of patients after a median duration of 8 days interquartile range (IQR = 7-14 days) and 23 of them (19.1\%) were persistent responders at 6 months. A similar findings were found in 2 uncontrolled clinical trials after a single injection of intra-articular methylprednisolone.
In these studies, compared with baseline, STV as determined by DCE-MRI, had decreased significantly in responder patients $1-2$ weeks after treatment, whereas in non-responders the value of STV increased [47, 48].

\section{Predictors of treatment response}

Identification of a clinical or imaging findings to predict response to IACS therapy in KOA was the topic of many RCTs and meta-analyses as well as a number of uncontrolled clinical studies. A few clinical or imaging parameters have been found to yield predictive ability (Table III and Table IV).

A relationship between synovitis with pain, swelling, effusion, and cartilage destruction [4, 10, 16, 34, 47, 48] suggests synovitis as a target for treatment as well as a parameter in predicting treatment response. Predictive accuracy of other parameters such as the presence of joint effusion, severity of symptoms at baseline, even predictive performance of just joint fluid aspiration alone, has been also investigated in a few studies [16, 49].

In 3 clinical trials, the presence of synovitis was a predictor of treatment response, and improvement of synovitis as detected by either ultrasound or MRI was significantly associated with reduction of knee pain [10, 34, 49].

In a recent 1-year prospective study of 132 patients with KOA the presence of pain or ultrasound-detected joint effusion one month after initiation of IACS treatment was predictor of treatment response at one year [41].

In contrast in an uncontrolled study neither synovitis nor effusion was predictor of treatment response, but higher scores of pain and the presence of patellar tendinopathy at baseline were predictors of significant 
Table IV. Uncontrolled clinical studies which addressed predictors of response to intra-articular corticosteroids in knee osteoarthritis

\begin{tabular}{|c|c|c|c|}
\hline Authors (year) & Type and purpose of studies & Treatment outcomes & $\begin{array}{l}\text { Predictors of response } \\
\text { to treatment }\end{array}$ \\
\hline $\begin{array}{l}\text { Pendelton et al. } \\
\text { (2008) [42] }\end{array}$ & $\begin{array}{l}\text { Study of } 86 \text { patients with } \\
\text { KOA }\end{array}$ & $\begin{array}{l}\text { Clinical improvement in } 70 \% \text { of } \\
\text { participants }\end{array}$ & $\begin{array}{l}\text { No predictor, including } \\
\text { no predictive ability of } \\
\text { ultrasound-detected synovitis }\end{array}$ \\
\hline $\begin{array}{l}\text { Wenham et al. } \\
\text { (2014) [47] }\end{array}$ & $\begin{array}{l}20 \mathrm{KOA} \text { treated with } 80 \mathrm{mg} \\
\text { IAMP }\end{array}$ & Reduction of pain and synovial volume & Presence of synovitis \\
\hline $\begin{array}{l}\text { O’Neill et al. } \\
\text { (2016) [10] }\end{array}$ & $\begin{array}{l}\text { Open-label prospective study, } \\
\text { efficacy of } 80 \mathrm{mg} \text { IAMP }\end{array}$ & $\begin{array}{l}\text { Reduction in pain and STV. A significant } \\
\text { association between change in the level } \\
\text { Of STV and change in level of pain }\end{array}$ & Synovitis \\
\hline $\begin{array}{l}\text { Fatimah et al. } \\
\text { (2016) [54] }\end{array}$ & $\begin{array}{l}174 \text { patients with KOA who } \\
\text { received IACS }\end{array}$ & $\begin{array}{c}\text { Improvement of pain > } 50 \% \text { compared to } \\
\text { baseline }\end{array}$ & $\begin{array}{l}\text { Age, range of movement, local } \\
\text { knee tenderness radiographic } \\
\text { score }\end{array}$ \\
\hline $\begin{array}{l}\text { Matzkin et al. } \\
(2017)[46]\end{array}$ & $\begin{array}{l}\text { Prospective study of } \\
100 \text { patients with } \\
\text { symptomatic KOA }\end{array}$ & Clinical improvement of pain & $\begin{array}{l}\text { Radiographic scores of grades } \\
1 \text { and } 2 \text { Kellgren and Lawrence }\end{array}$ \\
\hline $\begin{array}{l}\text { McCabe et al. } \\
\text { (2017) [51] }\end{array}$ & $\begin{array}{l}\text { Open-label study of patients } \\
\text { with symptomatic KOA } \\
\text { treated with } 80 \mathrm{mg} \text { IAMP }\end{array}$ & $\begin{array}{l}\text { To determine relationship between SF- } \\
\text { WBC count with pain and KOA severity }\end{array}$ & $\begin{array}{l}\text { Higher number of total } \\
\text { SF-WBC was predictor } \\
\text { of treatment response }\end{array}$ \\
\hline $\begin{array}{l}\text { Miletic et al. } \\
\text { (2018) [52] }\end{array}$ & $\begin{array}{l}\text { Prospective outcomes study } \\
\text { of } 117 \text { patients with KOA }\end{array}$ & Clinical improvement at all-time points & $\begin{array}{l}\text { Radiographic changes at } \\
\text { grade } 2 \text { OARSI }\end{array}$ \\
\hline $\begin{array}{l}\text { Maricar et al. } \\
\text { (2017) [53] }\end{array}$ & $\begin{array}{l}\text { Open-label study of } 207 \\
\text { patients with KOA }\end{array}$ & Evaluation of treatment response & Severity of cartilage damages \\
\hline $\begin{array}{l}\text { Bevers et al. } \\
(2014)[50]\end{array}$ & 62 patients with $\mathrm{KOA}$ & Pain reduction in $62 \%$ of study population & $\begin{array}{l}\text { Synovitis detected by } \\
\text { DCE-MRI }\end{array}$ \\
\hline $\begin{array}{l}\text { Gait et al. } \\
\text { (2016) [48] }\end{array}$ & $\begin{array}{l}\text { A clinical study of } 93 \text { patients } \\
\text { with KOA }\end{array}$ & $\begin{array}{c}\text { An association between changes in pain } \\
\text { and synovitis }\end{array}$ & $\begin{array}{l}\text { synovitis detected by } \\
\text { DCE-MRI }\end{array}$ \\
\hline
\end{tabular}

$D C E-M R I$ - dynamic contrast-enhanced magnetic resonance imaging, IACS - intra-articular corticosteroids, IAMP - intra-articular methylprednisolone, IATH - intra-articular triamcinolone hexacetonide, KOA - knee osteoarthritis, OARSI - Osteoarthritis Research Society International, SF-WBC - synovial fluid white blood cell count, STV - synovial tissue volume.

improvement. In this study $68 \%$ of patients had synovitis and $46 \%$ had joint effusion in clinical examination, and musculoskeletal ultrasound detected synovitis and effusion were found in $79 \%$ and $62 \%$ of patients respectively [42].

Similarly, in another prospective study by Bevers et al. [50] ultrasound-detected synovitis was not predictor of pain relief. This issue may indicate the existence of synovitis could not be detected by using current diagnostic methods or pain reduction in $\mathrm{KOA}$ is not related to suppression of synovitis alone. Higher number of synovial fluid white blood cells (SF-WBC) was predictor of treatment response in one study of patients with symptomatic knee osteoarthritis. In this study a single $80 \mathrm{mg}$ IAMP injection in subjects with higher total SF-WBC count was associated with greater pain reduction [51].

In some studies lower structural damages, age, local tenderness were predictors of treatment response [46, 52, 53]. In many studies no predictors were detected and even, the presence of synovitis was not predictor of treatment response [14, 46, 52-54]. In a meta-analysis of 21 studies by Hirsch et al. [55] none of clinical, sonographic or radiographic features of KOA were predictor of treatment response.

Nonetheless, Maricar et al. [49] in a meta-analysis of 11 studies found an association of treatment response with several parameters such as, joint effusion, joint fluid withdrawal, severity of disease, absence of synovitis, baseline severity, accuracy of intra-articular injection of corticosteroid. In this study identification of a specific predictor was impossible.

\section{Safety of intra-articular corticosteroids in knee osteoarthritis}

Long-term safety of IACS therapy in symptomatic KOA has been shown in 2 meta-analyses [20, 39]. In these studies adverse effects in the treatment and placebo groups were similar. In one meta-analysis local adverse effect in IACS group was lower than in IAHA 
group [39]. The safety of IACS has been also addressed in 2 RCTs [19, 36].

Raynauld et al. [36] found no deleterious anatomical structures changes despite of clinical improvement in patients taking repeated IACS every 3 months over 2 years of the study period.

By contrast, McAlindon et al. [19] in another RCT, found that repeated IACS every 3 months was associated with greater cartilage volume loss without any beneficial effect. Two observational studies $[56,57]$ found and association between IACS and progression of knee osteoarthritis.

However, the results of latter studies in assigning radiographic progression to IACS alone are limited because, several factors such as retrospective study design, patients selection, self-reported data regarding the type, time and number of IACS could confound the results.

Furthermore, patients with and without progressions have not been matched regarding baseline severity of osteoarthritis, as well as many associated factors of osteoarthritis progression. In addition, the safety outcome was not the primary objective of these studies.

The results of a meta-analysis of 40 studies which reviewed current literature on the effect of IACS on articular cartilage, supported the beneficial effects of IACS administration in knee osteoarthritis. In this study the impact of IACS on articular cartilage was time-and-dose dependent.

The beneficial effects were observed in studies with low doses of steroids and short duration of treatment, whereas high doses and long-term IACS therapy were associated with detrimental effects [58].

Overall, using intra-articular corticosteroids in KOA is relatively safe for short-term period, but its long-term effects on articular cartilage and other joint structures are unknown and remain to be determined [59].

\section{Limitations}

This study has several limitations, because, the studies included in this review were different in respect to study design, study population, patients characteristics, severity of structural damages, dosage of IACS, number of injections, duration of follow-up, treatment outcome and measures applied for assessment of treatment efficacy. In particular, the presence or absence of synovial inflammation and the method of diagnosis of synovitis is important. These factors can differently affect the results of treatment across studies.

Osteoarthritis is a multifactorial disease with heterogeneous phenotypes in terms of clinical manifestations and etiologies. Hence, knee osteoarthritis patients are classified to subgroups according to structural, etiolo- gical and epidemiological phenotypes. This classification system is helpful to identify a specific subgroup of patients who display inflammatory characteristics and thus may gain more benefit from anti-inflammatory treatment [60].

Therefore, in each study population response to treatment is expected to vary according to the etiology and structural changes, the presence or absence of risk factors. Clinical trials which were included in metaanalyses also differed in respect to study design, sample size, duration of study, statistic power and outcomes measures.

A number of clinical trial may lack important covariates or data which are necessary for detection of a significant differences in meta-analysis. These factors and many unknown confounding variables should be considered in confronting with controversies across different studies.

The main purpose of treatment in KOA is improvement of pain and function through suppression of synovial inflammation, and IACS is expected to affect only on anti-inflammatory component of pain [8].

As a results in subjects with advanced radiological $\mathrm{KOA}$ or in patients with coexistent associated factors of KOA progression efficacy of IACS is lower as compared with those who had mild disease without risk factors.

\section{Conclusions}

Existing data indicate that intra-articular corticosteroids in knee osteoarthritis provides a short-term pain relief and functional improvement which may last from one to several weeks.

At present, synovitis is the most important predictor of treatment response, and also a target for antiinflammatory treatment for intra-articular corticosteroids. Hence, subgroup of patients with inflammatory phenotype with clinical features of pain, stiffness joint swelling and effusion are expected to be more responsive than other phenotypes who do not display clinical manifestations of inflammation.

Nonetheless, identification of responder from nonresponder patients is challenging because, inflammatory presentation of KOA is temporal and is not present at all stages of the KOA process.

At present, patients with significant disability or advanced KOA who are non-responsive to standard therapy are considered for treatment with intra-articular corticosteroids.

Inefficiency of intra-articular corticosteroids in these patients is predictable, because in these subgroups, synovitis alone is not the cause of pain, but structural changes, mechanical and anatomical factors, and even extraarticular factors are also responsible, thus sup- 
pression of synovial inflammation by using IACS is likely to provide a short-term pain relief or no therapeutic benefit.

This issue is important, in particular patients who are expected to be respondent to IACS needs to be selected among population of KOA who have synovial inflammation with minimal or moderate anatomical abnormalities. Suppression of inflammatory process at early stages of KOA in addition to pain relief and functional improvement may prevent progression of structural changes.

Given an anti-inflammatory and chondroprotective properties of corticosteroids, the goals of future clinica trials should not be limited to short-term pain relief, but also prevention of osteoarthritis progression by identification of patients who not only have synovitis but they are also at higher risk of disease progression.

\section{Acknowledgements}

The authors want to thank Rouhani Hospital Clinical Research Development Unit in typing, data preparation and manuscript submission.

The authors also thank Mohammad Zamani (Student Research Committee, School of Medicine, and Babol University of Medical Sciences) for his contribution in providing flow diagram.

The authors declare no conflict of interest.

\section{References}

1. Heidari B. Knee osteoarthritis diagnosis, treatment and associated factors of progression: part II. Caspian J Intern Med 2011; 2: 249-255.

2. Mathiessen A, Conaghan PG. Synovitis in osteoarthritis, Arthritis Res The 2017; 19: 18, DOI 10.1186/s13075-017-1229-9.

3. Pelletier JP, Martel-Pelletier J, Abramson SB. Osteoarthritis, an inflammatory disease: potential implication for the selection of new therapeutic targets. Arthritis Rheum 2001; 44 1237-1247, DOI: 10.1002/1529-0131(200106)44:6<1237::AIDART214>3.0.CO;2-F.

4. Sellam J, Berenbaum F. The role of synovitis in pathophysiology and clinical symptoms of osteoarthritis. Nat Rev Rheumatol 2010; 6: 625-635, DOI: 10.1038/nrrheum.2010.159.

5. Scanzello CR, Goldring SR. The role of synovitis in osteoarthritis pathogenesis. Bone 2012; 51: 249-257, DOI: 10.1016/ j.bone.2012.02.012.

6. Babaei M, Javadian $\mathrm{Y}$, Narimani $\mathrm{H}$, et al. Correlation between systemic markers of inflammation and local synovitis in knee osteoarthritis. Caspian J Intern Med 2019; 10: 383-387, DOI: 10.22088/cjim.10.4.383.

7. Baker K, Grainger A, Niu J, et al. Relation of synovitis to knee pain using contrast-enhanced MRIs. Ann Rheum Dis 2010; 69: 1779-1783, DOI: 10.1136/ard.2009.121426.
8. Heidari B, Hajian-Tilaki K, Babaei M. Determinants of pain in patients with symptomatic knee osteoarthritis. Caspian J Intern Med 2016, 7: 153-161.

9. Heidari B, Javadian Y, Babaei M, Yousef-Ghahari B. Restorative effect of vitamin $D$ deficiency on knee pain and quadriceps muscle strength in knee osteoarthritis. Acta Med Iran 2015; 53: 466-470.

10. O'Neill TW, Parkes MJ, Maricar N, et al. Synovial tissue volume: a treatment target in knee osteoarthritis (OA). Ann Rheum Dis 2016; 75: 84-90, DOI: 10.1136/annrheumdis-2014-206927.

11. Mora JC, Przkora R, Cruz-Almeida Y. Knee osteoarthritis: pathophysiology and current treatment modalities. J Pain Res 2018; 11: 2189-2196, DOI: 10.2147/JPR.S154002.

12. Heidari B, Hajian K. Role of corticosteroid in knee osteoarthritis. JIMC 2005; 23: 118-123 [In Persian].

13. Rozental TD, Sculco TP. Intra-articular corticosteroids: an updated overview. Am J Orthop (Belle Mead NJ) 2000; 29: 18-23.

14. Jones A, Doherty M. Intra-articular corticosteroids are effective in osteoarthritis but there are no clinical predictors of response. Ann Rheum Dis 1996; 55: 829-832, DOI: 10.1136/ ard.55.11.829.

15. Conaghan PG. Corticosteroid injections in osteoarthritis: should we care about predicting response? Towards a better understanding of the drivers of peripheral pain. Rheumatology 2013; 52: 966-967, DOI: 10.1093/rheumatology/ket123.

16. Gaffney K, Ledingham J, Perry JD. Intra-articular triamcinolone hexacetonide in knee osteoarthritis: factors influencing the clinical response. Ann Rheum Dis 1995; 54: 379-381, DOI: 10.1136/ard.54.5.379.

17. D'Agostino MA, Conaghan P, Le Bars M, et al. EULAR report on the use of ultrasonography in painful knee osteoarthritis. Part 1: prevalence of inflammationin osteoarthritis. Ann Rheum Dis 2005; 64: 1703-1709, DOI: 10.1136/ard.2005.037994.

18. Roemer FW, Guermazi A, Felson DT, et al. Presence of MRI-detected joint effusion and synovitis increases the risk of cartilageloss in knees without osteoarthritis at 30-month follow-up: the MOST study. Ann Rheum Dis 2011; 70: 1804-1809, DOI: 10.1136/ard.2011.150243.

19. McAlindon TE, LaValley MP, Harvey WF, et al. Effect of intraarticular triamcinolone vs saline on knee cartilage volume and pain in patients with knee osteoarthritis: a randomized clinical trial. JAMA 2017; 317: 1967-1975, DOI: 10.1001/jama.2017.5283.

20. Jüni P, Hari R, Rutjes AW, et al. Intra- articular corticosteroid for knee osteoarthritis. Cochrane Database Syst Rev 2015; 22: CD005328, DOI: 10.1002/14651858.CD005328.pub3.

21. Hepper C, Halvorson JJ, Duncan ST, et al. The Efficacy and duration of intra-articular corticosteroid injection for knee osteoarthritis: a systematic review of level. J Am Acad Orthop Surg 2009; 17: 638-646, DOI: 10.5435/00124635-200910000-00006.

22. Telikicherla M, Kamath SU. Accuracy of needle placement into the intra-articular space of the knee in osteoarthritis patients for viscosupplementation. J Clin Diagn Res 2016; 10: RC15-RC17, DOI: $10.7860 / J C D R / 2016 / 17127.7275$.

23. Altman RD, Devji T, Bhandari M, et al. Clinical benefit of intraarticular saline as a comparator i.n clinical trials of knee osteoarthritis treatments: a systematic review and meta-analysis of randomized trials. Semin Arthritis Rheum 2016; 46: 151-159, DOI: 10.1016/j.semarthrit.2016.04.003. 
24. Gasparyan AY, Ayvazyan L, Blackmore H, Kitas GD. Writing a narrative biomedical review: considerations for authors, peer reviewers, and editors. Rheumatol Int 2011; 31: 14091417, DOI: 10.1007/s00296-011-1999-3.

25. Li W, Abram F, Pelletier J, et al. Fully automated system for the quantification of human osteoarthritic knee joint effusion volume using magnetic resonance imaging. Arthritis Res Ther 2010; 12: R173, DOI: 10.1186/ar3133.

26. Maricar N, Callaghan MJ, Parkers MJ, et al. Clinical assessment of effusion in knee osteoarthritis - a systematic review. Semin Arthritis and Rheum 2016; 46: 556-563, DOI: 10.1016/j.semarthrit.2015.10.004.

27. Wang X, Hunter DJ, Jin X, Ding C. The importance of synovial inflammation in osteoarthritis: current evidence from imaging assessments and clinical trials. Osteoarthritis Cartilage 2018; 26: 165-174, DOI: 10.1016/j.joca.2017.11.015.

28. Sarmanova A, Hall M, Moses J, et al. Synovial changes detected by ultrasound in people with knee osteoarthritis - a metaanalysis of observational studies. Osteoarthritis Cartilage 2016; 24: 1376-1383, DOI: 10.1016/j.joca.2016.03.004.

29. Torres L, Dunlop DD, Peterfy C, et al. The relationship between specific tissue lesions and pain severity in persons with knee osteoarthritis. Osteoarthritis Cartilage 2006; 14: 1033-1040, DOI: 10.1016/j.joca.2006.03.015.

30. Wang X, Jin X, Han W, et al. Cross-sectional and longitudinal associations between knee joint effusion synovitis and knee pain in older adults. J Rheumatol 2016; 43: 121-130, DOI: 10.3899/jrheum.150355.

31. Hill CL, Hunter DJ, Niu J, et al. Synovitis detected on magnetic resonance imaging and its relation to pain and cartilage loss in knee osteoarthritis. Ann Rheum Dis 2007; 66: 1599-1603, DOI: 10.1136/ard.2006.067470.

32. Zhang $\mathrm{Y}, \mathrm{Nevitt} M$, Niu J, et al. Fluctuation of knee pain and changes in bone marrow lesions, effusions, and synovitis on magnetic resonance imaging. Arthritis Rheum 2011; 63: 691699, DOI: 10.1002/art.30148

33. Felson DT, Niu J, Neogi T, et al. Synovitis and the risk of knee osteoarthritis: the MOST Study. Osteoarthritis Cartilage 2016; 24: 458-464, DOI: 10.1016/j.joca.2015.09.013.

34. Chao J, Wu C, Sun B, et al. Inflammatory characteristics on ultrasound predict poorer longterm response to intraarticular corticosteroid injections in knee osteoarthritis. J Rheumatol 2010; 37: 650-655, DOI: https://doi.org/10.3899/jrheum. 090575.

35. Conaghan PG, Hunter DJ, Cohen SB, et al. Effects of a single intra-articular injection of a microsphere formulation of triamcinolone acetonide on knee osteoarthritis pain: a double-blinded, randomized, placebo-controlled, multinational study. J Bone Joint Surg Am 2018; 100: 666-677, DOI: 10.2106/ JBJS.17.00154.

36. Raynauld JP, Buckland-Wright C, Ward R, et al. Safety and efficacy of long-term intraarticular steroid injections in osteoarthritis of the knee: a randomized, double-blind, placebocontrolled trial. Arthritis Rheum 2003; 48: 370-377, DOI: 10.1002/art.10777.

37. Liu SH, Dubé CE, Eaton CB, et al. Longterm effectiveness of intraarticular injections on patient-reported symptoms in knee omsteoarthritis. J Rheumatol 2018; 45: 1316-1324, DOI: 10.3899/jrheum.171385.
38. Bannuru RR, Natov NS, Obadan IE, et al. Therapeutic trajectory of hyaluronic acid versus corticosteroids in the treatment of knee osteoarthritis: a systematic review and meta-analysis. Arthritis Rheum 2009; 61: 1704-1711, DOI: 10.1002/art.24925.

39. Arroll B, Goodyear-Smith F. Corticosteroid injections for osteoarthritis of the knee: meta-analysis. BMJ 2004; 328: 869, DOI: 10.1136/bmj.38039.573970.7C.

40. He WW, Kuang MJ, Zhao J, et al. Efficacy and safety of intraarticular hyaluronic acid and corticosteroid for knee osteoarthritis: a meta-analysis. Int J Surg 2017; 39: 95-103, DOI: 10.1016/j.ijsu.2017.01.087.

41. Calvet J, Orellana C, Galisteo C, et al. Clinical and ultrasonographic features associated to response to intraarticular corticosteroid injection. A one year follow up prospective cohort study in knee osteoarthritis patient with joint effusion. PLoS One 2018; 13: e0191342, DOI: 10.1371/ journal.pone.0191342.

42. Pendleton A, Millar A, O'Kane D, et al. Can sonography be used to predict the response to intra-articular corticosteroid injection in primary osteoarthritis of the knee? Scand J Rheumatol 2008; 37: 395-397, DOI: 10.1080/03009740802050738.

43. Pyne D, loannou Y, Mootoo R, Bhanji A. Intra-articular steroids in knee osteoarthritis: a comparative study of triamcinolone hexacetonide and methylprednisolone acetate. Clin Rheumatol 2004; 23: 116-120, DOI: 10.1007/s10067-003-0841-z.

44. Lomonte AB, de Morais MG, de Carvalho LO, Zerbini CA. Efficacy of triamcinolone hexacetonide versus methylprednisolone acetate intraarticular injections in knee osteoarthritis: a randomized, double-blinded, 24-week study. J Rheumatol 2015; 42: 1677-1684, DOI: 10.3899/jrheum.150297.

45. Buyuk AF, Kilinc E, Camurcu IY, et al. Compared efficacy of intra-articular injection of methylprednisolone and triamcinolone. Acta Ortop Bras 2017; 25: 206-208, DOI: 10.1590/1413785220172505172581

46. Matzkin EG, Curry EJ, Kong Q, et al. Efficacy and treatment response of intra-articular corticosteroid injections in patients with symptomatic knee osteoarthritis. J Am Acad Orthop Surg 2017; 25: 703-714, DOI: 10.5435/JAAOS-D-16-00541.

47. Wenham CY, Balamoody S, Grainger AJ, et al. The responsiveness of novel, dynamic, contrast-enhanced magnetic resonance measures of total knee synovitis after intra-articular corticosteroid for painful osteoarthritis. Osteoarthritis Cartilge 2014; 22: 1614-1618, DOI: 10.1016/j.joca.2014.05.024.

48. Gait AD, Hodgson R, Parkes MJ, et al. Synovial volume vs synovial measurements from dynamic contrast enhanced MRI as measures ofresponse in osteoarthritis. Osteoarthritis Cartilge 2016; 24: 1392-1398, DOI: 10.1016/j.joca.2016.03.015.

49. Maricar N, Callaghan MJ, Felson DT, O'Neill TW. Predictors of response to intra-articular steroid injections in knee osteoarthritis - a systematic review. Rheumatology (Oxford) 2013 52: 1022-1032, DOI: 10.1093/rheumatology/kes368.

50. Bevers K, Zweers MC, Vriezekolk JE, et al. Are ultrasonographic signs of inflammation predictors for response to intra-articular glucocorticoids in knee osteoarthritis? Clin Exp Rheumatol 2014; 32: 930-934.

51. McCabe PS, Parkes MJ, Maricar N, et al. Brief report: synovial fluid white blood cell count in knee osteoarthritis: association with structural findings and treatment response. Arthritis Rheumatol 2017; 69: 103-107, DOI: 10.1002/art.39829. 
52. Miletic I, Agten C, Sutter R, et al. Relationship of radiographic osteoarthritis severity with treatment outcomes after imaging-guided knee injections: a prospective outcomes study. Rofo 2018; 190: 134-143, DOI: 10.1055/s-0043-112337.

53. Maricar N, Parkes MJ, Callaghan MJ, et al. Structural predictors of response to intra-articular steroid injection in symptomatic knee osteoarthritis. Arthritis Res Ther 2017; 19: 88, DOI 10.1186/s13075-017-1292-2.

54. Fatimah N, Salim B, Raja EU, Nasim A. Predictors of response to intra-articular steroid injections in patients with osteoarthritis of the knee joint. Clin Rheumatol 2016; 35: 2541-2547, DOI: 10.1007/s10067-016-3365-z.

55. Hirsch G, Kitas G, Klocke R. Intra-articular corticosteroid injection in osteoarthritis of the knee and hip: factors predicting pain relief - a systematic review. Semin Arthritis Rheum 2013; 42: 451-473, DOI: 10.1016/j.semarthrit.2012.08.005.

56. Zeng C, Lane NE, Hunter DJ, et al. Intra-articular corticosteroids and the risk of knee osteoarthritis progression: results from the Osteoarthritis Initiative. Osteoarthritis Cartilage 2019; 27: 855-862, DOI: 10.1016/j.joca.2019.01.007.

57. Simeone FJ, Vicentini JRT, Bredella MA, Chang CY. Are patients more likely to have hip osteoarthritis progression and femoral head collapse after hip steroid/anesthetic injections? A retrospective observational study. Skeletal Radiol 2019; 48: 14171426, DOI: 10.1007/s00256-019-03189-x.

58. Wernecke C, Braun HJ, Dragoo JL. The effect of intra-articular corticosteroids on articular cartilage: a systematic review. Orthop J Sports Med 2015; 3: 2325967115581163, DOI: 10.1177/ 2325967115581163.

59. Kijowski R. Risks and benefits of intra-articular corticosteroid injection for treatment of osteoarthritis: what radiologists and patients need to know. Radiology 2019; 293: 664-665, DOI: 10.1148/radiol.2019192034.

60. Grässel S, Muschter D. Recent advances in the treatment of osteoarthritis. F1000Res 2020; 9: F1000 Faculty Rev-325, DOI: 10.12688/f1000research.22115.1. 